\title{
Plans To Join With Our Society
}

\author{
FRED ROBINSON, REGINA
}

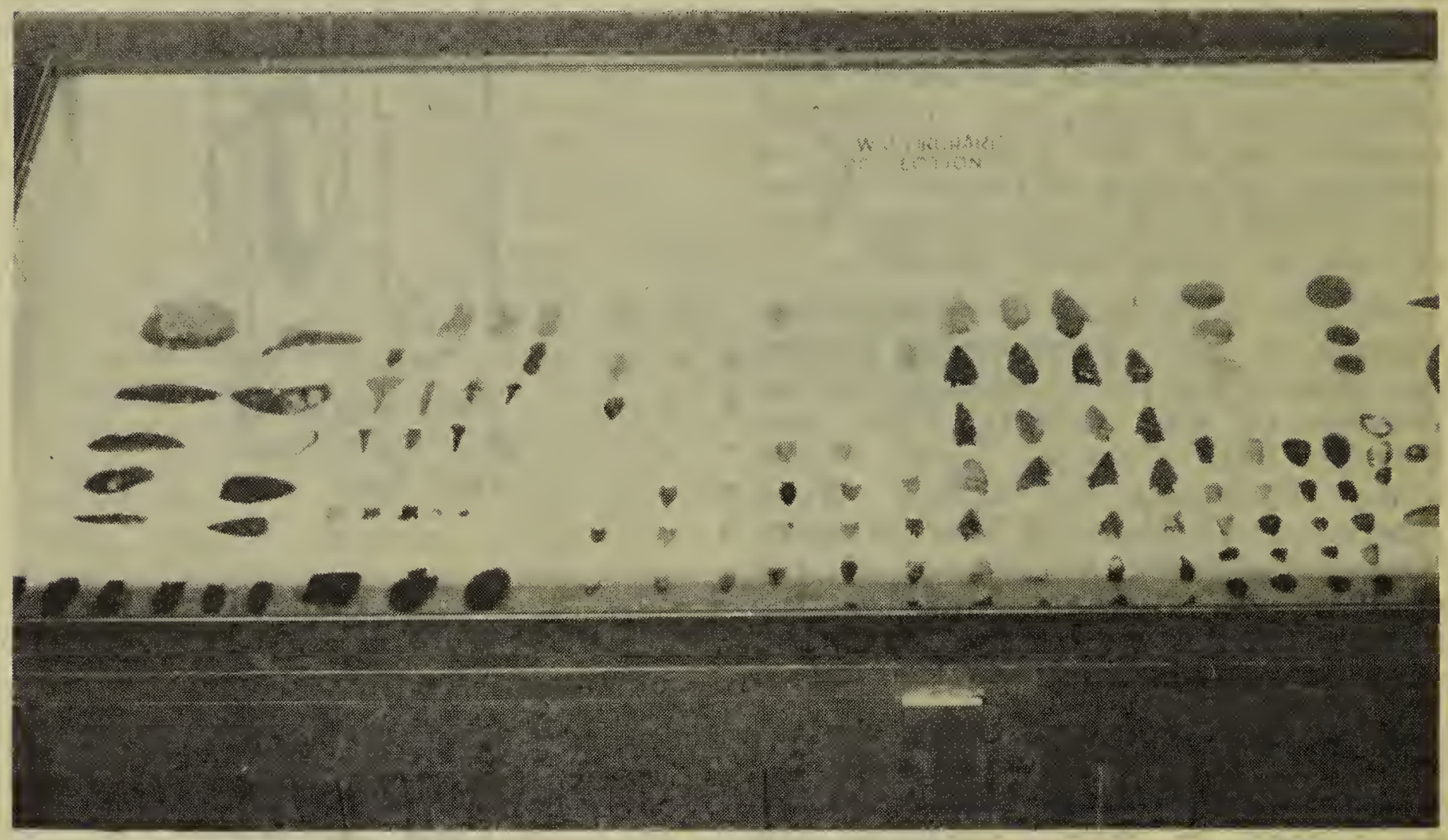

The Saskatchewan Archaeological Society, at a recent meeting, voted to join the Saskatchewan Natural History Society, and propose to operate as a unit within our Society. At a later Executive meeting of the Natural History Society it was agreed to accept this arrangement, subject to final ratification at our annual meeting.

This adds to our growing list of members, one hundred or more people interested in Archaeology who will receive the Blue Jay. The Archaeological Society will publish in the Blue Jay material which, up to now, was published in their bulletin Spade and Screen.

The joining of these two societies should be a step fcrward for both. The aims of the two are similar- that of conservation, preservation of prehistoric and historic sites, recording of data regarding archaeological and other finds, and spreading interest in Natural History generally.

The Archaelogical Society was founded twenty years ago by the late Mr. W. J. Orchard, whose stone-age collection is now in our Provincial Museum. A photo of part of this collection is shown here. Mr. Orchard wrote two books on Saskatchewan's stone age and was for a time editor of Spade and Screen.

We urge all those interested in stone age relics and studies to support the Blie Jay and submit material of interest for publication.

Send your items to the Blue Jay editor, at 1077 Garnet St., Regina. 